\title{
Exploring Media Architecture Design in Virtual Design Environments
}

\author{
A Case Study of Undergrad Architecture Studio \\ Waldemar Jenek (i) \\ Queensland University of Technology | CSIRO's Data61, Brisbane, Australia. \\ Glenda Caldwell \\ Queensland University of Technology Brisbane, Australia. \\ Jared Donovan \\ Queensland University of Technology, Brisbane, Australia. \\ Veronica Garcia Hansen () \\ Queensland University of Technology, Brisbane, Australia. \\ Matt Adcock (1) \\ CSIRO's Data61, Canberra, Australia. \\ Mingze XI () \\ CSIRO's Data61, Canberra, Australia.
}

Received: November 13th 2020, Accepted: November 21th 2020

Refer: Jenek, W., Caldwell, G., Donovan, J., Garcia Hansen, V., Adcock, M., XI, M., (2020), Exploring Media Architecture Design in Virtual Design Environments, Journal of Design Studio, V.2, N.2, pp 159-163,

W. Jenek ORCID: 0000-0001-8771-9111, G. Caldwell ORCID: 0000-0003-0837-9310, J. Donovan ORCID: 0000-0002-8025-1947, V. Garcia Hansen 0000-0001-5934-5554, M. Adcock ORCID: 0000-0001-6191-9887, M. XI ORCID: 0000-0003-1291-4136, DOI: $10.46474 /$ jds. 825715 https://doi.org/10.46474/jds.825715

\begin{abstract}
This case study explores how architecture students can learn to design media architecture within virtual design environments tools. The target participants of this study are advanced (i.e. 3rd year) architecture students at the University of Applied Science, Bochum, Germany. To evaluate the student-experience, students were asked to develop a media architecture structure during the semester. Once the project finished the students provided feedback via surveys and interviews. The feedback was analysed employing thematic analysis. The case study shows that students are curious about technology in the design process and that technology has a growing relevance in an architecture career. The feedback will be used to improve future teaching approach.
\end{abstract}

Keywords: Design Education, Design Studio, Immersive Design Environment, Media Architecture, Virtual Reality.

\section{Introduction}

Architecture does not have to be something static anymore; it can be interactive and/or temporary and capable of shifting in a short time to address different problems or needs. Media Architecture is an emerging discipline which incorporates materials or objects with dynamic properties, such as interactive sources of light or moving elements, that embody physical space on an architectonic scale. Most Media Architecture installations allow dynamic interaction or show interactive content (Brynskov et al, 2015).
Immersive virtual design environments (VDE) refers to a digital environment that allows the users to interact with the digital space with devices such as VR-headset (Obeid, 2019). In this case study Virtual Reality was used with Twinmotion and VR-headsets to explore the design of Media Architecture in an undergraduate architecture studio. VDEs have the potential to refine the methods and tools of existing design processes in Media Architecture. In higher education context, they can refine the traditional teaching approaches while discovering new

Journal of Design Studio, v:2 n:2

Jenek, W., Caldwell, G., Donovan, J., Garcia Hansen, V., Adcock, M., XI, M., (2020), Exploring Media Architecture Design in 
ways of design thinking and design solutions in architecture schools (Obeid, 2019). The purpose of this case study is to investigate virtual design environments, such as virtual reality, as a design-decision-making tool in the education process of architecture with the focus of learning about technology. It uses a modified version of Kellers ARCS Models (Attention, Relevance, Confidence, Satisfaction) (Keller, 2010). Students were asked to design a Media Architecture structure employing virtual-design-environment tools. Besides, interviews and surveys were conducted with the students to research their perceptions of the learning experience to provide recommendations for teaching architecture design using virtual-design-environment tools in the design process of Media Architecture.

\section{Background}

Virtual design environments and Media Architecture are typically not incorporated in traditional architecture curriculum at the undergraduate level when learning how to design buildings (Zhigang as cited in Haeusler et al., 2012). Zhigang (as cited in Haeusler et al., 2012) outlines that Media Architecture projects are not just shiny lights on the building. In his opinion, the purpose and function of Media Architecture cannot be designed and developed with traditional architectural approaches. He argues that new and advanced technological solutions for Media Architecture require novel approaches in the design process to be taught and learned. In response to this and to address the dynamic elements of Media Architecture this case study explores the implementation of virtual design environments with undergraduate architecture students in Germany. Most of the literature regarding design studio education focuses on how to implement software in a traditional design studio context (Gonavaram Bala Sai, 2004; Gross \& Do, 1999; Guney, 2015; Kuhn, 2001; Salman et al., 2008) with limited perspectives on immersive virtual design environments for architecture. Therefore, it is necessary to introduce techniques for learning architectural design that allow students to engage, visualise, communicate, test, and develop Media Architecture with dynamic properties.

\section{Study Design}

This case study was conducted as part of an undergraduate architecture studio in Germany in December 2019. The study was designed as a five-day design intensive workshop with a mixture of lectures and design studio activities to allow students to address the assignment brief. Students were asked to design a small interactive Media Architecture structure. Figure 1 is an example of the student work that was visualised in Twinmotion during the studio.

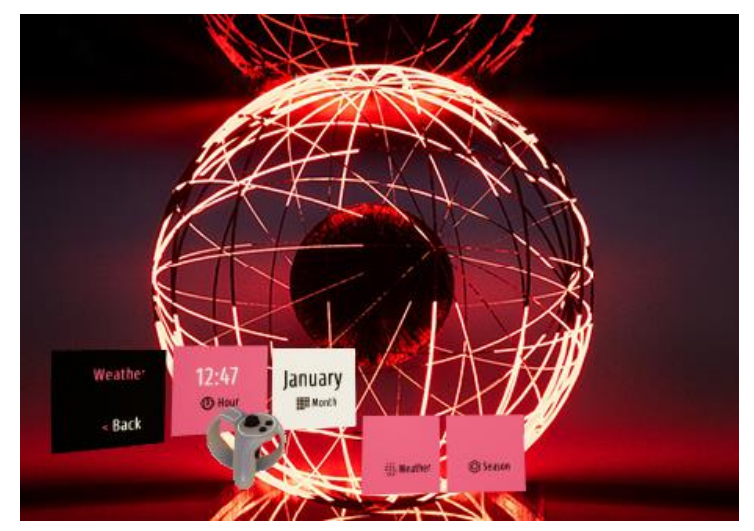

Figure 1: Student Project by Ahsen Cavlak

This study employed qualitative methods of data collection such as semi-structured interviews $(n=10)$ and surveys $(n=9)$ with participating students, and observations conducted by the lead author. Ethical clearance was approved from the Queensland University of Technology QUT Human Research Ethics Committee and complied with the requirements for a negligible or low risk application (approval number: 1900000811). Design researchers such as Wei et al., (2015), Salman et al., (2008) or Mathews (2010) have used the architectural design studio to investigate the effects of technologies in the context of architectural education. This case study works to expand on their findings to further examine the impact of immersive virtual design environments. The recruiting process took place in October 2019 where students could elect to participate in this studio and the research. The participants were a mixture of undergraduate architecture students at different year levels. Overall the design studio had 28 students, and 27 submitted a project. 


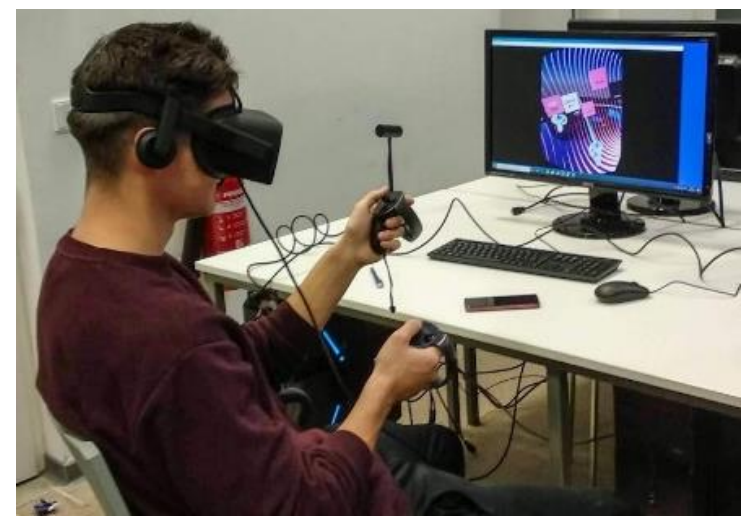

Figure 2. Student using VR Headset, photo by the author

Students used Twinmotion (Epic Games, 2020) which is real-time immersive $3 \mathrm{D}$ architectural visualization software for virtual reality and Archicad (Graphisoft, 2020) a common architectural drawing and 3D modelling software. All students had access to high-performance hardware and two virtual reality headsets (oculus rift and HP mixed reality headset) to engage with the learning content as part of the proposed immersive virtual design environment as seen in Figure 2. The qualitative data from the interviews and surveys was analysed using thematic analysis (Braun \& Clarke, 2013). Therefore, following steps have been conducted: familiarisation with the data, initial coding, searching for themes, reviewing themes, defining themes, reporting findings (Braun \& Clarke, 2013). Keller's ARCS motivational model (Keller, 2010), which explores the attention, relevance, confidence and satisfaction that students experience was used as a framework to evaluate the themes that emerged. The following section presents and discusses the findings in relation to the ARCS model. During the interviews, the first author careful communicated to students that critical responses and evaluations were welcome and that the purpose of the study was to improve the pedagogical approach of the design studio. Data for the evaluation of the design studio were drawn from student questionnaire and interview responses as well as observations of the learning activity by the researcher. These data were analysed to inform a recommendation for the use of virtual design environment tools in architectural education. Data was analysed by the first author to categorize themes of importance and gaps in understanding. While broadly similar in approach to studies such as Obeid (2019) and Wei et al., (2015), the analysis taken here followed a more qualitative approach in order to understand student experience and show evidence of learning success employing Keller's ARCS Model.

\section{Findings: Student Learning Transformation} The data shows that students are highly motivated to employ developed skills in future design projects. The themes that were identified are organised under the ARCS model sub-headings.

\section{Attention}

A leading emerging theme of the conducted interviews and surveys is the significant interest in the field of extended reality. Students believe virtual design environments are an addition to the traditional design process rather than being an alternative.

Immersive design environment: One of the main emerging themes is there is a significant interest in the field of immersive design environment. Students describe the benefit of the perception of the space experiences their design proposal in virtual reality and how it allows them to make more sophisticated design decisions. Students made additional comments that immersive experiences are engaging, as they differ from other tools they have previously employed. All students enjoyed using immersive reality tools, but some express criticism if these technologies are necessary for the design process. Most students agreed that designing in a virtual design environment has an impact on their discussions, and a small number did not believe that their design ideas are impacted by the tool.

Non-immersive design environment: One of the students outlined the limitation of CAD software within the design process. He argued that he would only design looking at a screen but not experiencing space. Thus, this is an indicator of

Journal of Design Studio, v:2 n:2

Jenek, W., Caldwell, G., Donovan, J., Garcia Hansen, V., Adcock, M., XI, M., (2020), Exploring Media Architecture Design 
the need to employ an immersive design environment to foster a more bodily experience within the general design process.

\section{Relevance}

Students described virtual design environments as relevant for future work with clients. All participants agreed that the developed skills would have an impact on future design units mainly on the CAD skillset limitation. Many agreed to see the benefit of a future career, such as client interaction. All students agreed that the developed skills would have an impact on future design units mainly on the CAD skillset limitation. Using virtual immersive environment tools is seen more as an addition to visualisation architecture, rather than to test dynamic properties such as changing light sources, displays and moving elements. Students mentioned that they had been limited in developing their design ideas because of their limited knowledge of the immersive technology as it was new to them in the context of the architecture studio.

Content Understanding and Issues: Students had trouble defining Media Architecture, augmented reality and virtual reality or connect these topics with each other. At the beginning of the workshop, students described that they had trouble understanding the design task, which became more evident after the lecture. They indicated that they would have liked to have more time working and designing with virtual-reality headsets. One participant believed that the themes of Media Architecture and virtual design environments were not the central concept that were meant to be understood within this workshop, which indicates that the explanation of the software tools overtook the learning experiences. Therefore, the definition of Media Architecture and virtual design environments have to be presented with more depth to ensure that student comprehend these novel concepts.

Previous learning experiences: One student illustrated the limitation of their skillset at the beginning of their studies in their first assignment. He expressed a deep learning success after the workshop in reporting that the perception of this limitation disappeared. He was confident to use the software as a tool and does not feel the constraints anymore.

Identified knowledge gap: Students reported that there is a lack of software-skill-knowledge, this gap is limiting their design ideas, as students are more likely to stick to an idea which is easier to display in CAD then something complicated.

\section{Confidence}

Students reported that they are confident to employ the skills they have gained and learned in the workshop for their future architectural design work.

Learning Format: Students stated that questions during the workshop were addressed successfully. Students reported that they had the opportunity to explore VDEs themselves but also that there was enough time for the tutor to take care of the questions. Students enjoyed the clear structure of the workshop, split into two main parts. The first part was about learning the $\mathrm{CAD}$ and visualisation software, and the other part was a hands-on design task. On the one hand, students could employ their new skills immediately on a design task, and one the other hand, they could still access support from a tutor if something did not work out. Hence, this is an indicator to keep a clear, separated structure in the proposed learning and teaching design. In addition to that, some participants report that they enjoyed the speed of content delivery. They described that there was enough time to think things through and consider if they had missed something, but it was also not boring, which would lead to a loss of attention. Further, participants described the little breaks in between as a positive aspect; it allowed them to repeat the content for themselves or help others while the tutor was walking around helping with questions. Thus, fostering students to talk to each other and reflect for a short amount of time in between the primary content delivery helped to foster the student community experiences. This approach encouraged a collaborative design studio culture. 
Satisfaction: Students reported that they were happy overall with their design and reported tremendous learning success. Many of them said that the limitation of the software tool was better understood. Students reported that they were satisfied with their design which resulted despite the short amount of time they had to work on it, regardless that they realised there is room for improvement. Therefore, students could prove their concept with the new tools and did not get frustrated because of their limitation of the knowledge how to employ the tools. The amount of content they produced was appropriate for that level of learning and in comparison, to other architectural studio outcomes.

\section{Conclusion/ Future Work}

Students were curious about Media Architecture and how to design it. The data analysis showed that there is a knowledge gap in understanding Media Architecture and virtual design environments. Students mix the definitions of the concept of Media Architecture as physical interactive structure with the virtual design environment, which was employed as a design tool. Besides, the content for the following case studies as part of a larger research project will be adjusted to place more emphasis on the understanding of Media Architecture and virtual design environments as design tools.

\section{References}

Braun, V., \& Clarke, V. (2013). Successful qualitative research: A practical guide for beginners. SAGE.

Brynskov, M., Dalsgaard, P., \& Halskov, K. (2015). Media Architecture: Engaging Urban Experiences in Public Space. In J. Lossau \& Q. Stevens (Eds.), The Uses of Art in Public Space (pp. 51-66). http://site.ebrary.com/id/10994059

Epic Games. (2020, November 13). Twinmotion. https://www.unrealengine.com/enUS/twinmotion

Gonavaram Bala Sai, S. S. (2004). Interactive teaching model: A proposal to integrate basic architectural design pedagogy with digital media [M.S., University of Missouri - Columbia]. http://search.proquest.com/docview/30516291 2/abstract/9DAE3AE8C951488BPQ/13

Graphisoft. (2020, November 13). Archicad. https://graphisoft.com/

Gross, M., \& Do, E. (1999). Integrating digital media in design studio: Six paradigms. Proceedings of the American College Schools of Architecture Conference, Minneapolis, gub.

Guney, D. (2015). The Importance of Computer-aided Courses in Architectural Education. Procedia - Social and Behavioral Sciences, 176, 757-765.

https://doi.org/10.1016/j.sbspro.2015.01.537

Haeusler, M. H., Tomitsch, M., Tscherteu, G., \& Berkel, B. van. (2012). New media facades: A global survey. Avedition.

Keller, J. M. (2010). Motivational Design for Learning and Performance. Springer US. https://doi.org/10.1007/978-1-4419-1250-3

Kuhn, S. (2001). Learning from the architecture studio: Implications for project-based pedagogy. International Journal of Engineering Education.

Mathews, J. M. (2010). Using a Studio-Based Pedagogy to Engage Students in the Design of Mobile-Based Media. English Teaching: Practice and Critique, 9(1), 87-102.

Obeid, S. (2019). The influence of virtual reality on design process creativity in basic design education [PhD Thesis]. Bilkent University.

Salman, H., Laing, R., \& Conniff, A. (2008). The Changing Role of CAAD in the Architectural Design Studio. The Built and Human Environment Review, 1, 25.

Wei, X., Weng, D., Liu, Y., \& Wang, Y. (2015). Teaching based on augmented reality for a technical creative design course. Computers \& Education, 81 , 221-234. https://doi.org/10.1016/j.compedu.2014.10.017 